\title{
Ahmed Essa with Othman Ali, The Muslim Contribution to the Renaissance
}

Herndon, VA: International Institute of Islamic Thought, 2010.

$$
\text { pbk. } 312 \text { pages }
$$

Despite this being the age when information is readily available, the analysis, the dissemination, and the effect of pioneering Islamic knowledge in all fields is a relatively recent endeavor with only a handful of books that cover these areas from an academic point of view. The Muslim Contribution to the Renaissance is a comprehensive addition; it is a collection of numerous examples of Islamic innovation, and places these examples in 
their historical context in direct relation to the developing West - a time called the "Dark Ages" in Europe and the "Golden Age" in the Muslim world. This Golden Age was one of high calibre scholasticism and practical exploration in all fields, and it directly influenced the emergence in the West of what was to be called the "Renaissance."

With fifteen chapters, the book begins with: Chapter 1: "Islam's Role in History," Chapter 2: "Learning and Islamic Civilization," Chapter 3: "The Establishment of the First Muslim Community," Chapter 4: "The Islamic World Order," and Chapter 5: "Islamic Civilization in Europe and West Asia." These chapters discuss the unique relationship of knowledge and Islam as expressed in the linguistics of the Qur'an; the chapters also cover the Muslim societies of learning that emerged and improved the lifestyles of followers in areas such a egalitarianism, law, education, and charity.

The remaining chapters are specialized, covering particular areas of Islamic exploration and academic development from the seventh to the eighteenth centuries AC in the three continents in which there were Muslims. The Islamic quest for knowledge in all fields was dynamic and widespread, absorbing from the various cultures Islam encountered (the Greek, Indian, Persian, Chinese), and translating and adding interpretations and innovations. The fluid movement within the Islamic empire of the diverse sources of knowledge radically changed and affected Europe-from trade to farming, to science and medicine, to the arts.

Chapter 6: "Trade," elaborates on the highly sophisticated and important role of trade in the Islamic world. Trade not only improved the quality of life for all inhabitants - Muslim and non-Muslim - but served to connect and spread ideas, materials, technologies, and banking. These ideas spread to Europe by way of Sicily and Spain.

Chapter 7: "Agriculture and Technology," covers changes in the varieties of crops and food products, as well as cultivation methods, technology, and engineering. The Muslim empire was dynamic and evolving, and experimented successfully with the development of crops in new locations, with the transplanting of seeds, and with the development of an assortment of crops in every region they settled in. In countries in Europe where Muslims were established, there were other developments in cultivation, including irrigation and technology, which improved the crop yield and quality of life.

Chapter 8: "Flowering of Islamic Learning," discusses the growing impetus of knowledge in the Islamic world with centers of learning, research, and education in major cities like Baghdad and Cairo. These institutes 
of higher learning - including systems of examination (by oral dissertation) and library collections - served as model repositories of knowledge, which were visited by and ultimately emulated by Europeans. Also documented are the many Muslim women who achieved prestige in learning, religious knowledge, medical knowledge, and literature throughout the Islamic empire.

Chapter 9: "The Sciences," is an exhaustive chapter, covering in detail the prototypical development of Muslim science beyond the translations of Greek works, to include exploration and innovation and many important discoveries and works in mathematics, astronomy, and geographyachievements that shaped the way we look at these disciplines today. With their investigations in algebra, Al-Khwarizmi and Omar Khayyam are among the many that radically changed the face of the mathematics.

Chapter 10: "Medicine," is almost equally as exhaustive as the previous chapter-with many of the same great thinkers overlapping into both of these disciplines. It covers the well-established primary role Muslims played in developing medicine into a scientific and elevated profession. In addition, Muslims were credited for the development of regulated and professional pharmaceutics and patient care. Key figures - such as al-Razi, Ibn Sina, al-Kindi, and Ibn Rushd-practiced and wrote about medicine, and for centuries, translations of their texts served as texts for many medical schools in Europe.

Chapter 11: "Arabic Literature," and Chapter 12: "Persian Literature," both deal with the expressive nature of Muslim texts, which were primarily written in Arabic but also in Persian. Like the other fields, the literature of the Muslims benefitted from many different cultural sources throughout the empire and yet was shaped into a unique entity with a distinctly Muslim ethos, which expressed the morals and aspirations of the religion and the desire for expressive beauty in all forms of existence, including language. By focusing on translations, evocative expression, and form, this text describes some of the influences of the literature of Muslims on Europe.

Chapter 13: "The Arts," touches on only a select few examples of the arts; it does not maintain the rigor and variety of investigation evidenced in the previous chapters. The examples chosen were described in terms of their beauty and ingenuity. However, despite the rich base of material available, the influence and affect of Islamic arts on European architecture and art is not discussed.

Chapter 14: "Ottoman Contribution to Islamic civilization," however, brilliantly makes up for the lack of analysis in Chapter 13 with a focus on 
the unique position of the Ottoman empire-especially its being between Europe and the rest of the Islamic world. The art and architecture of this empire was a dynamic absorption, a significant development, and a unique vision - all of which encompassed innovative structural developments and aesthetic expressions in various media. Their effect on Europe and the Renaissance extends through the centuries of Ottoman rule.

Chapter 15: "Islamic Impact on the Renaissance," is a wonderful culmination chapter, which summarizes the specific instances and general changes to Europe because of the Islamic empire as the irrefutable link that led to the emergence of the Renaissance. Many key figures in the development of European are quoted, noting the influence of Islamic works on their own. Here, as in most parts of the book, Western references are used to substantiate the phenomenon of Islamic influence. The authors, however, acknowledge that because of plagiarism, the influence in the various areas of knowledge was not always credited to the original Muslim authors when their works were translated into European languages.

The plurality of influence, the fluidity of transference, and the dynamism of development engendered the creation of many brilliant thinkers or polymaths who wrote profusely and experimented in many different fields from medicine to mathematics and astronomy to philosophy and the arts. These polymaths including great thinkers - such as Ibn Rushd, Ibn Sina, Umar al Khayyam, al-Kwarizami and countless others who came before them-and these people were often more prolific and effective than many of the subsequent "Renaissance men" celebrated in Western history.

There is not a better time to revisit the innovations of these eras and to understand the roots and underpinnings of so much knowledge that is taken for granted. The organization and fluidity of the arguments in the book are exceptionally clear, and readers from any academic background will find the material accessible and interesting - even if the reader is only specialized in one area, the demonstrated polymath spirit of inquiry is contagious.

Tammy Gaber, $\mathrm{PhD}$ Assistant Professor of Architecture, Department of Engineering, British University in Egypt Adjunct Professor, Department of Performing Visual Arts, American University in Cairo email: tammygaber@yahoo.ca and tammygaber@gmail.com 